\title{
Multi-parameter integrated experimental analysis of wall compaction effect on Semi-automatic plastering machine
}

\author{
Minghua DONG ${ }^{1, a}$, Zhenyu YANG ${ }^{2}$ \\ ${ }^{1}$ Department of Mechanical Engineering, Shandong Labor Vocational and Technical College, Jinan, China \\ ${ }^{2}$ School of Mechanical Engineering, Shandong University of Technology, Zibo, China
}

\begin{abstract}
Semi-automatic wall plastering machine can effectively reduce the labor intensity of workers, increase operational efficiency in the construction process. A problem is solved how to select its work parameters. In order to obtain the best working conditions of a certain wall plastering machine, this paper has studied hydrostatic compaction process of the wall plastering machine. According to "Standard of the Architectural Decoration Project Quality Approval" in China, mortar compaction effects in cases of different plastering speed, rotation speed of the screw auger, and mortar consistency have been obtained by experiments. Using static-pressure method for wall plastering, experimental results showed that the best plastering speed, screw auger rotation speed and mortar consistency is in the range of $17 \sim 18.2 \mathrm{~cm} / \mathrm{s}, 55 \sim 65 \mathrm{r} / \mathrm{min}$ and $78 \sim 86 \mathrm{~mm}$.
\end{abstract}

\section{INTRODUCTION}

With the development and progress of society, in the case of main engineering standards for housing, the people have become increasingly high demanding on the quality of housing interior wall surface. If the flatness, verticality and compactness do not meet the requirements, it will directly affect the quality and effectiveness of follow-up interior decoration. It is very important how to improve the quality of the interior decoration, especially indoor aesthetic plastering quality. Level of technology varies from person to person by hand plastering. According to the average level of technology workers of the construction market in recent years, the perpendicularity and flatness and compactness of the plaster have improved with the help of tools, but deviation is larger. The wall plastering machine had been designed $[1,2]$ (device as shown in Fig. 1) and solved the problem. As long as the builders had strictly checked on the quality of the variety of building materials, plastering perpendicularity and flatness of walls are able to easily control within the tolerance range by using the advanced plastering. However, the degree of compaction is related to a number of factors, and is difficult to control $[3,4]$.

\section{Proposed research}

Compaction effects of wall are the key to assure wall strength and quality. The control of the degree of compaction is an important indicator to ensure the compaction effect of the wall. If the wall does not meet the requirements of compaction degree will result in local dents, crackle, delamination, and blister phenomenon.

\footnotetext{
a Corresponding author: dmh-1976@163.com
}

Through research of the plastering machine plaster speed, screw auger rotation speed and consistency of mortar, the best working status of the wall plastering machine is achieved, which to guide the construction operations, improve economic efficiency.

\section{The affect analysis of the plastering speed on the compaction effect}

As shown in Fig. 1, the plastering device makes the vertical motion on the cylindrical guide rail after the wall plastering machine and the plastering device from bottom to top positioning. When the plastering device moving down, the mortar will be plastered up the wall (this is the most major characteristic of this wall plastering machine: mortar will not fall from the top of the wall $[1,5])$, the upward movement will be the idle stroke.

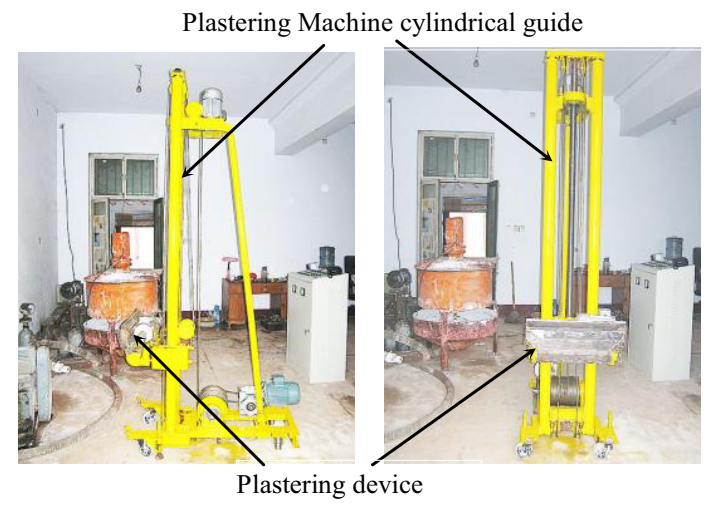

Fig. 1 Wall plastering machine and plastering device 
Experimental results are obtained under the following conditions:

1. The height of experiment wall is $3.2 \mathrm{~m}$, indoor wall, and clay brick structures, dealt with as required [6].

2. The mortar pump model is UB3.0, the maximum working pressure is $5 \mathrm{MPa}$, the inlet hose diameter is $64 \mathrm{~mm}$, the outlet hose diameter is $51 \mathrm{~mm}$. The length of experimental transmission hose is $10 \mathrm{~m}$, the maximum height of the terminal hose is $3.09 \mathrm{~m}$, and the pressure of the terminal hose is $0.3 \mathrm{MPa}$.

3. The proportion of cement, lime, sand in experimental mortar is 1:1:4, and deployment of consistency through experience.

4. The plastering layer thickness is $1.2 \mathrm{~cm}$, and the plastering layer width is $60 \mathrm{~cm}$ at a time.

5. Collection plastering speed using the HJH8-R2236 type photoelectric/ mechanical speed device. The steel straight ruler measures thickness of the plaster. The mortar consistency measures by $\mathrm{SC}-145$ digital instrument of mortar consistency.

6 . The plastering device working pressure is $0.2 \mathrm{MPa}$ on the wall surface.

Such as shown in Fig. 2, it is the compaction effects of the different plastering speeds. From which can be seen as the plastering speed increases, wall crack, delamination, and blister phenomenon increases, and the dropping mortar increases too, so wall quality deteriorates. When plastering speed is less than $18.2 \mathrm{~cm} / \mathrm{s}$, they change very little. But plastering speed is too slow that will affect the progress of the project. When plastering speed is greater than the $18.2 \mathrm{~cm} / \mathrm{s}$, the number of crackle, delamination and blister increases can no longer meet the acceptance criteria of plastering the walls. Therefore, in the case of best plastering machine plaster speed range is $17 \sim 18.2 \mathrm{~cm} / \mathrm{s}$.

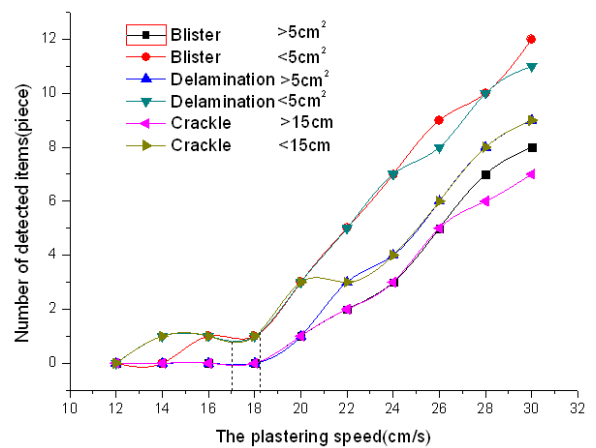

Fig. 2 The affect of the plastering speed on the compaction effect

\section{The affect analysis of the screw auger rotation speed on the compaction effect}

When the wall plastering machine works, the pressure between the plastering machine and the wall surface comes from the end of the mortar pump hose and screw auger rotating pressure (screw auger shaft in plastering machine is located as shown in Fig. 3). When mortar pump is normally working, changing variable-frequency motor output speed can change screw auger rotation speed, so it can change mortar pressure in the plastering device.

Such as shown in Fig. 4, it is the compaction effects of the different screw auger rotation speed, when the plastering speed is $17.6 \mathrm{~cm} / \mathrm{s}$.

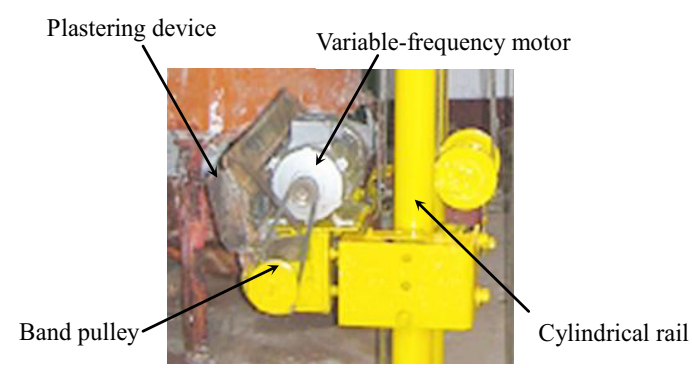

Fig. 3 Wall plastering machine and plastering device

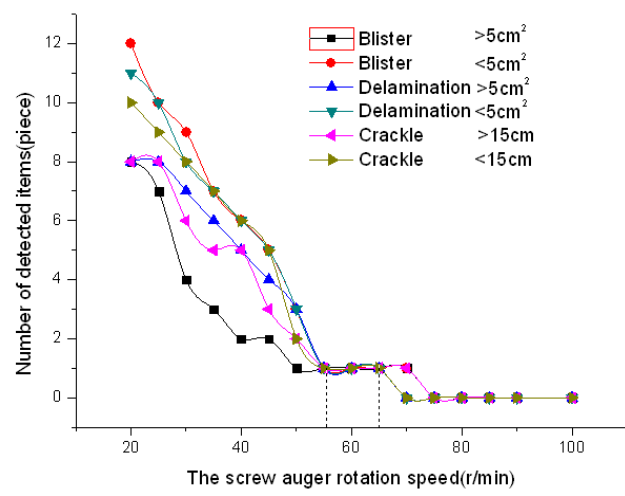

Fig. 4 The affect of the screw auger rotation speed on the compaction effect

As can be seen from the Fig. 4, when screw auger rotation speed increases, wall crackle, delamination and blister phenomenon decreases, and the dropping mortar decreases too, so wall quality became better. When screw auger rotation speed is greater than $55 \mathrm{r} / \mathrm{min}$, these changes are smaller. But when the speed is less than $55 \mathrm{r} / \mathrm{min}$, there has a sharp increase in the number of crackle, delamination and blister phenomenon. It can no longer meet the acceptance criteria of plastering the walls. In this condition, the best plastering machine screw auger rotation speed range is $55 \sim 65 \mathrm{r} / \mathrm{min}$.

\section{The affect analysis of the mortar consistency on the compaction effect}

The mortar consistency has a great impact on the compaction effect. When the wall plastering machine plasters on the wall, the plastering speed is $17.6 \mathrm{~cm} / \mathrm{s}$, screw auger rotation speed is $60 \mathrm{r} / \mathrm{min}$. The compaction effects of the different mortar consistency are shown in Fig. 5. As it can be seen from the Fig. 5, the boundary of consistency is $83 \mathrm{~mm}$. 


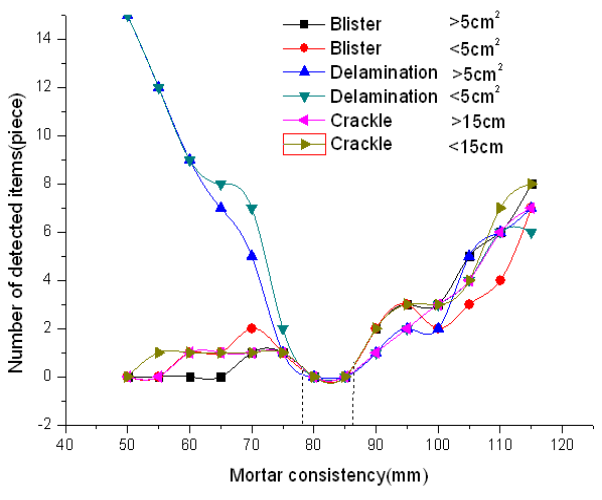

Fig. 5 The affect of the mortar consistency on the compaction effect

With the mortar consistency increases, walls crackle, delamination, blister, dropping mortar phenomenon also increases, quality of the wall surface became worse. When mortar consistency decreases, there is less crackle and blister, poor adhesion effect of mortar on the wall and poor quality of wall, but the delamination of wall surface and the falling mortar became proliferation. When the consistency of mortar $>86 \mathrm{~mm}$ or $<78 \mathrm{~mm}$, it can no longer meet the acceptance criteria of plastering the walls. Therefore, the best mortar consistency of the wall plastering machine is $78 \sim 86 \mathrm{~mm}$.

\section{Conclusions}

As shown in Fig. 6, it is the best result after the construction of wall with the wall plastering machine. Here the plastering speed is $17.6 \mathrm{~cm} / \mathrm{s}$, screw auger rotation speed is $60 \mathrm{r} / \mathrm{min}$ and consistency of mortar is $82 \mathrm{~mm}$. It has been tested to meet the wall plastering acceptance criteria with fast speed of construction and low rate of rework.

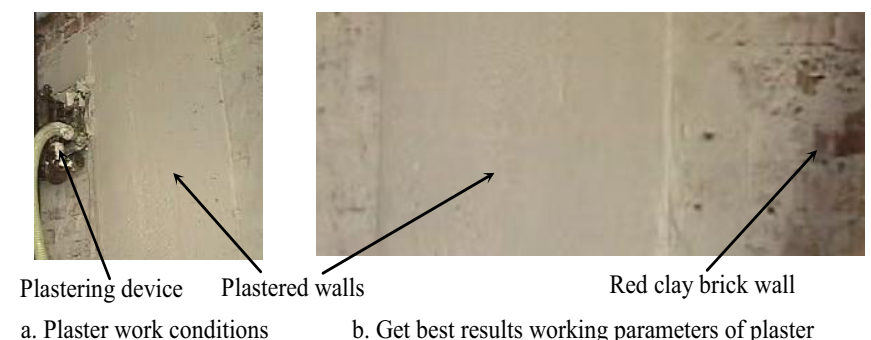

Fig. 6 The plaster results of the optimal working parameters

This paper has analyzed the plastering speed, the rotation speed of screw auger and mortar parameter of the wall plastering machine by experiments, and has gained the compaction effect of the wall with changing in these parameters. Conclusions show that the best plastering speed is in the range of $17 \sim 18.2 \mathrm{~cm} / \mathrm{s}$, the best rotation speed of screw auger is in the range of $55 \sim 65 \mathrm{r} / \mathrm{min}$, and the best mortar consistency range is $78 \sim 86 \mathrm{~mm}$. The wall plastering machine has received a better economic efficiency in actual construction.

\section{References}

1. Zhenyu Yang, Chuangen Gong and Zhixia Liu: Construction Machinery, Vol. 27(8), pp. 84-85, 2007. (In Chinese)

2. Zhenyu Yang, Yong Wang and Xingbo Zhang: Journal of XI'AN University of Architecture \& Technology (Natural Science Edition), Vol. 45(5), pp. 750-754, 2013. (In Chinese)

3. Zhi Liu: Shanxi Hydrotechnics, Vol. 44(3), pp. 61-62, 2007. (In Chinese)

4. Enping Wang, Wei Xu: Coal Project, Vol. 26(11), pp. 30-31, 2004. (In Chinese)

5. Dapeng Wang: SHANXI ARCHITECTURE, Vol. 9(30), pp. 43-44, 2004. (In Chinese)

6. Shaohua Jin, Lei Shen: Zhejiang Construction, Vol. 22(123), pp. 60-61, 2003. (In Chinese) 